\title{
Opportunistic management for rangelands not at equilibrium
}

\author{
MARK WESTOBY, BRIAN WALKER, AND IMANUEL NOY-MEIR
}

\section{Abstract}

We discuss what concepts or models should be used to organize research and management on rangelands. The traditional range succession model is associated with the manazement objective of achieving an equilibrium condition under an equilibrium grazing policy. In contrast, the state-and-transition model would describe rangelands by means of catalogues of alternative states and catalogues of possible transitions between states. Transitions often require a combination of climatic circumstances and management action (e.g., fire, grazing, or removal of grazing) to bring them about. The catalogue of transitions would describe these combinations as fully as possible. Circumstances which allow favorable transitions represent opportunities. Circumstances which threaten unfavorable transitions represent hazards. Under the state-andtransition model, range management would not see itself as establishing a permanent equilibrium. Rather, it would see itself as engaged in a continuing game, the object of which is to seize opportunities and to evade hazards, so far as possible. The emphasis would be on timing and flexibility rather than on establishing a fixed policy. Research under the state-and-transition model would aim to improve the catalogues. Frequencies of relevant climatic circumstances would be estimated. Hypotheses about transitions would be tested experimentally. Often such experiments would need to be planned so that they could be implemented at short notice, at an unknown future time when the relevant circumstances arise.

\section{Key Words: equilibrium, climax, succession, models}

Applied ecology disciplines such as range management necessarily are organized around a model as to how their ecosystem functions. By a model we mean a system of concepts, generalizations, or assumptions. The model guides what data are collected, and how that information is assembled so as to arrive at management decisions. This paper discusses the choice of models for managing rangelands. The discussion will contrast 2 clearly distinct models which we will call the "range succession model" and the "state-andtransition model". However it should be understood that these represent 2 ends of a spectrum of possibilities. By contrasting the extremes, we hope to bring out the issues clearly.

Up to the present most range managers have been taught concepts much closer to the range succession model than to the stateand-transition model (Lewis 1969, Tueller 1973, Heady 1975, Stoddart, Smith and Box 1975, Smith 1988). The range succession model has not gone unchallenged. On the contrary, a number of range scientists have criticised it. The main criticisms are summarized later. However, despite the scientific criticisms, most management continues to be organized by reference to the range succession model.

Accordingly our purpose in this paper is not to criticise the range succession model further at the level of scientific evidence or the-

\footnotetext{
Authors are respectively associate professor, School of Biological Sciences, Macquarie University, NSW 2109, Australia; chief, CSIRO Division of Wildlife and Ecology, PO Box 84, Lyneham, ACT 2602, Australia; professor, Department of Botany, The Hebrew University of Jerusalem, Jerusalem, Israel.

We wish to warmly thank John Lud wig for suggesting we get together to write this paper. Drafts have benefitted from comments of Dawn Bazely, David Hik, Don Jameson, Bob Jefferies, John Ludwig, Peter Sundt, Neil West, Walt Whitford, and an anonymous reviewer.

Manuscript accepted 23 January 1989.
}

ory, but rather to develop alternative ways of formulating existing knowledge for purposes of management. The state-and-transition model is the alternative we consider. We discuss how research and management would be affected if the state-and-transition model were to be widely used instead of the range succession model.

\section{The Range Succession Model}

The successional approach to range management derives from Clementsian ideas of plant ecology (Clements 1916, Weaver and Clements 1938, Tobey 1981). It was suggested very early (Sampson $1917,1919)$. US government agencies developed it into a practical system of range classification. In the 1940's and 1950's it became firmly established as the consensus of the range management profession, expressed in the first 2 editions of Stoddart and Smith (1943, 1955), in the masterly review by Ellison (1960), and in a series of conceptual papers in the journals of the profession (Humphrey 1945; Dyksterhuis 1949, 1958; Parker 1954; Hanson 1957).

The model supposes a given rangeland has a single persistent state (the climax) in the absence of grazing. Succession towards this climax is a steady process. Grazing pressure produces changes which are also progressive and are in the opposite direction to the successional tendency. Therefore the grazing pressure can be made equal and opposite to the successional tendency, producing an equilibrium in the vegetation at a set stocking rate. A sustainable yield of livestock products can be harvested from such an equilibrium. All possible states of the vegetation can be arrayed on a single continuum (Fig. 1a) from heavily-grazed, early-successional, poor condition, to ungrazed, climax, excellent condition. Condition is the technical term for the vegetation's position on this continuum. Trend is the term for the vegetation's travel along the continuum. Much research effort has been devoted, and still is, to developing methods for assessing and monitoring condition and trend on particular rangelands. Under the range succession model the object of management is to choose a stocking rate which establishes a long-term balance between the pressure of grazing and the successional tendency.

The model recognizes that vegetation is affected when rainfall varies from year to year. A balance between the pressure of grazing and the successional tendency of the vegetation can not produce a completely unvarying equilibrium. The range succession model deals with varying rainfall by supposing that drought affects vegetation in a similar way to grazing, and conversely that aboveaverage years have effects which can be understood as accelerating the successional tendency (Fig. 1b). Therefore, under the range succession model, management should respond to drought by reducing grazing pressure, so that the combined pressure of drought and grazing varies as little as possible, the balance of these combined pressures with the successional tendency is maintained, and the position of the vegetation on the condition scale is stabilized.

Under the range succession model research and management proceed as follows. Resource inventory classifies and maps rangelands according to their climax-type, and within each climax-type, according to current condition. Grazing trials determine whether range condition improves or deteriorates from various condition classes at various stocking rates (Fig. 2, arrows). These trials 


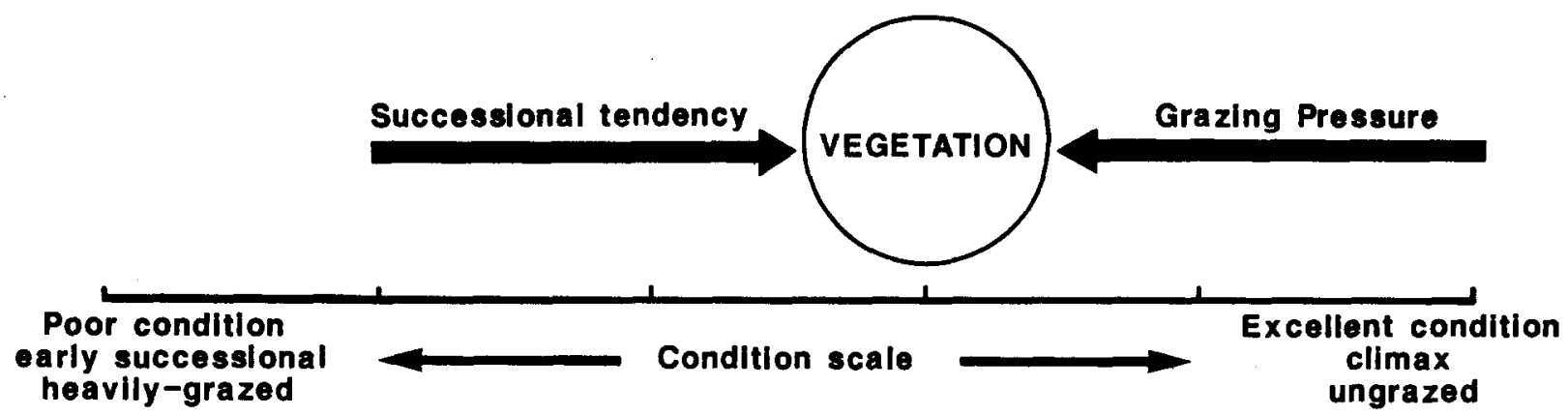

\section{(b) INCORPORATION OF RAINFALL VARIABILITY \\ IN THE RANGE SUCCESSION MODEL}

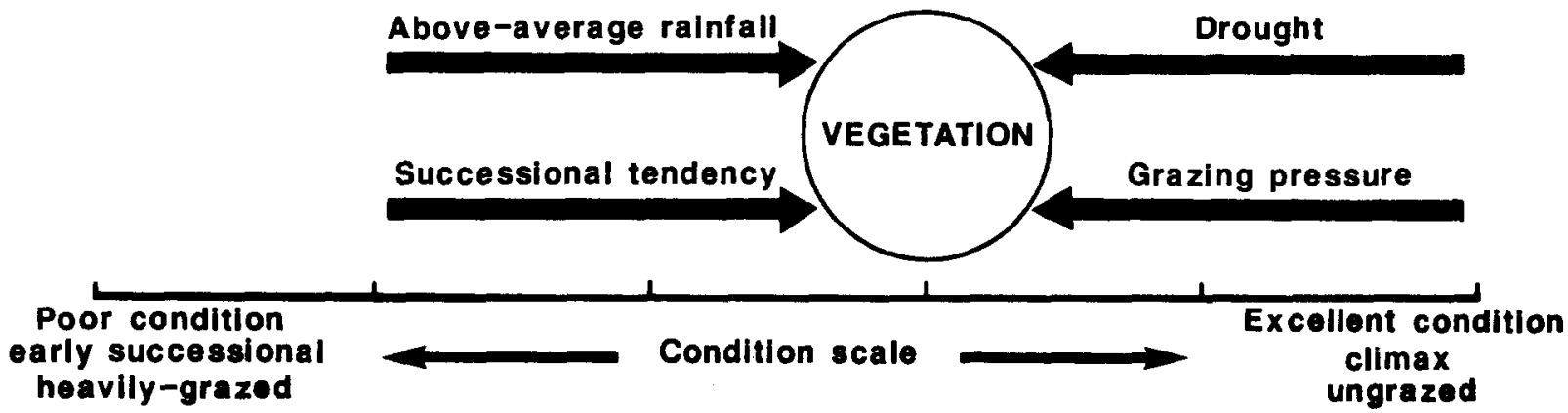

Fig. 1.(a) General scheme of the range succession model. (b) Incorporation of rainfall variability in the range succession model. See text for further explanation.

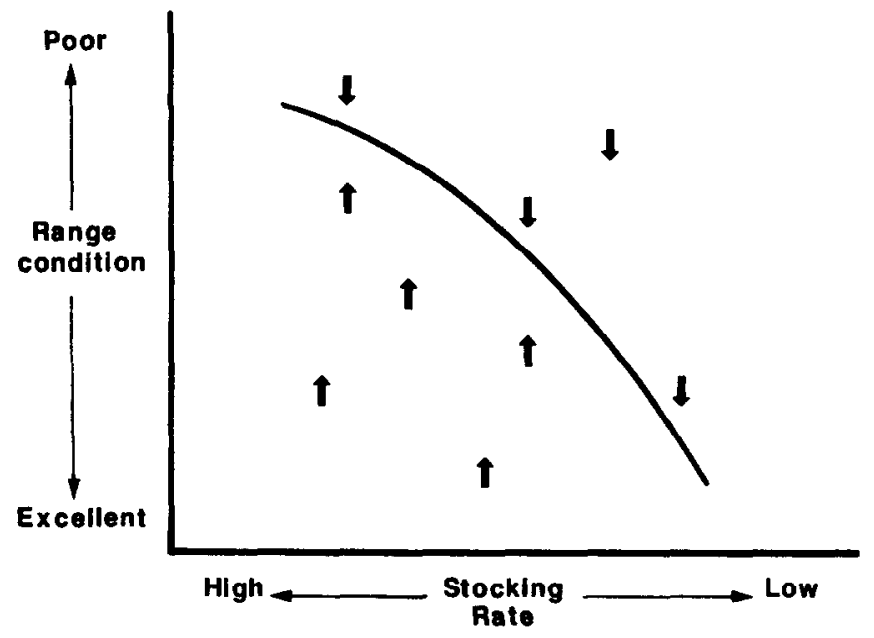

Fig. 2. Schematic relations between stocking rate and range condition under the range succession model. See text for further explanation.

estimate, for every stocking rate, the range condition level it maintains at equilibrium, or conversely for every condition level, the stocking rate necessary to just maintain it (Fig. 2, curve). The range succession model operates on the assumption that range condition can be modified continuously and reversibly along this curve by adjusting the stocking rate to a constant level and giving time for the range to equilibrate with it. The main tool of range management is the level of stocking rate. By adjusting stocking, condition can be tuned until the desired combination of both variables is reached, and fixed there. The desired combination may be one which maximizes long-term livestock production per unit area, or maximizes long-term income, or maintains production per head or range condition at some acceptable level. Grazing trials can estimate livestock production per animal at each possible conditionlevel of the rangeland, and this information can be used along with price and cost assumptions to estimate at what combinations of stocking rate and range condition these various objectives are optimized.

We have said we believe the essential features of the traditional range management approach are encapsulated in the range succession model. However, one major exception must be mentioned. Range scientists have for many years devoted a great deal of research effort to "grazing systems", a topic which sounds very general but has come to refer to systems involving deferred and rotational grazing patterns (e.g., Wilson et al. 1984). In these systems pastures are subdivided and animals are moved among the subdivisions such that each receives both rest and grazing periods. The purpose can be to reduce the selectivity with which animals can graze, or to provide a rest from grazing at particular times of year. 
Each subdivision can be grazed in a set pattern through time, or more recently various degrees of flexibility are recommended in response to actual plant growth and to the annual cycle of plant phenology. To the extent that from year to year the average grazing pressure is not intended to vary, grazing systems can still be viewed within the framework of the range succession model. Range condition is still regarded as a continuous variable and range management as aiming to keep condition at equilibrium.

\section{Limitations of the Range Succession Model}

Range scientists have accumulated substantial empirical evidence of cases where the assumptions of the range succession model do not hold. Theoretical ideas have developed which explain why the assumptions often should not hold.

Vegetation changes in response to grazing have often been found to be not continuous, not reversible, or not consistent. When livestock have been removed from desert shrublands and desert grasslands, the vegetation has often not changed at all (Norris 1950, Paulsen and Ares 1962, Turner 1971, Smith and Schmutz 1975, Smeins et al. 1976, West et al. 1984), or has not changed in the direction predicted by the model (Glendening 1952, Buffington and Herbel 1965, Rice and Westoby 1978), or has simply increased in quantity without substantial changes in species composition (Gardner 1950, Robertson 1971). Perennial grasslands in environments with strongly seasonal rainfall typically have been converted to annual grasslands by grazing. But when grazing has been stopped, they have often not reverted to perennial grass dominance (Biswell 1956, Heady 1958, Naveh 1967, Le Houerou 1972, Tueller 1973). South African sourish-mixed veld (Acocks 1953, Walker et al. 1986) and British hill Nardus pastures (Rawes 1981) become dominated by unpalatable species when grazed continuously at moderate intensity, so that livestock are able to select the more palatable grasses. However if the dominance proceeds too far, they do not revert to a more palatable mixture when livestock are excluded.

In recent years, there have been several attempts to re-evaluate and broaden the theoretical basis of range management in general, and the range succession model in particular. A consciousness of the problem was apparent at the 1984 International Rangelands Congress (e.g. Noble 1986, Foin 1986, Anderson 1986, Mentis 1986). Adaptive management, linked to formal modelling, has been advocated (Jameson 1988). Multivariate methods have been used to reduce the subjectivity of inventory (West 1988). Efforts by the Society for Range Management and some U.S. government agencies to revise range assessment procedures have been reviewed by Smith (1988).

The re-thinking of the theory of range dynamics parallels theoretical development in ecology generally. Clementsian concepts of single equilibrium communities and deterministic succession pathways are no longer as dominant in ecology as when they were first applied to the practical problem of range management. Current ecological theory allows for alternative stable states, discontinuous and irreversible transitions, nonequilibrium communities, and stochastic effects in succession (e.g. Drury and Nisbet 1973, Connell and Slatyer 1977, May 1977, Wiens 1977, Noble and Slatyer 1980, Price 1980, Price et al. 1984, Strong et al. 1984).

Mechanisms are found on rangelands which are known to produce complex ecosystem dynamics of these sorts. Examples have previously been reviewed (Noy-Meir 1975, Westoby 1980, Walker (1988 and in press). Here we briefly summarize the main categories:

a) Demographic inertia. Some plant populations may require a rare event for establishment to occur, but once this has occurred, the resulting cohort can persist for a long time. Several examples have been reported in Australian rangelands (Williams 1970, Williams and Roe 1975, Crisp and Lange 1976, Crisp 1978, Lange and
Graham 1983, Griffin and Friedel 1985). Neilson (1986) interpreted vegetation change on rangelands in southern New Mexico in terms of particular climatic events leading to mass establishment or mortality of particular species. In turn, he related these to long-term patterns in global climatology.

b) Grazing catastrophe. Grazer intake and plant net growth and reproduction respond to plant abundance according to nonlinear functions. These functions are shaped in such a way as to suggest that plant abundance may vary discontinuously and irreversibly in response to changes in stocking rate (Noy-Meir 1975, 1978, 1982; Walker et al. 1981; Walker and Noy-Meir 1982; Crawley 1983). Thus alternative persisting states are possible. For instance, a preferred species may be able to persist under a given stocking rate as long as it is sufficiently abundant to satiate grazers' requirements for it; but if once reduced to a low level, it may not be able to persist or reestablish under the same stocking rate (Westoby 1974, NoyMeir 1981).

c) Priority in competition. Alternative stable states may result when the outcome of competition depends on the initial abundances of the competitors. For example, the adults of each species may have an advantage over seedlings of the other, or interference effects such as allelopathy or shading may be involved.

d) Fire positive feedback. Some vegetation components, e.g., many grasses, promote fire and are also themselves promoted by fire. Woody plant populations may be competitively superior once established, but sensitive to fire in the seedling stage. The state dominated by woody plants may be less prone to fire than grassland. Such mechanisms can produce alternative persisting states in vegetation composition.

e) A vegetation change that triggers a persisting change in soil conditions (e.g., surface erosion) may not be reversible on a timescale relevant to management.

Each one of these mechanisms may produce alternative persisting vegetation states. Where they are important, single events of weather, fire, grazing, or management action may change rangelands in ways which are not simply reversible and are not consistent with the classical range succession model.

In rangelands where none of these mechanisms are important, the classical model should be adequate to explain and predict vegetation changes. However, both evidence and theory suggest that one or several of these mechanisms are important in many rangelands, in particular in arid and semiarid regions. There is need for an alternative general model for vegetation change in such rangelands.

\section{An Alternative, State-and-Transition Model}

We propose that in many situations rangeland dynamics can usefully be described by a set of discrete "states" of the vegetation on one piece of ground and a set of discrete "transitions" between states. In some instances it is also convenient to recognize "transient states" in which a rangeland does not persist indefinitely, but rather changes into one or other persisting states, depending on events while it is in the transient state.

"Transitions" between states are triggered by natural "events" (e.g., weather, fire) or by management "actions" (change in stocking rate, burning, destruction or introduction of plant populations, fertilization). Very often a combination of the 2 may be needed. Transitions may occur very quickly (as in a fire) or over an extended period (as while a cohort of woody plants grows up). In either case, however, the system does not come to rest halfway through a transition.

A state is necessarily an abstraction encompassing a certain amount of variation in space and time. The advantages of a stateand-transition formulation are clear in dealing with situations where rangeland dynamics actually consist of clearly-defined dis- 


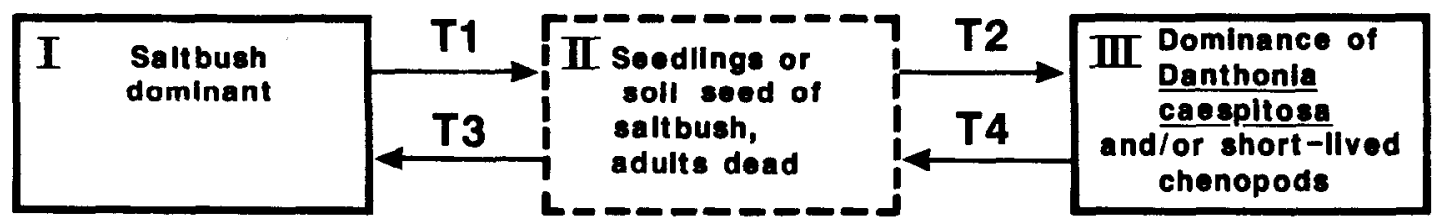

Fig. 3. State-and-transition diagram for Example 1: Bladder saltbush (Atriplex vesicaria) on heavy clay soil in the Australian Riverine Plain. Catalogues in Box 1.

In the examples given here other states could be produced by capital intensive management such as ploughing, reseeding or fertilizing. It would be possible to include them within a state-and-transition system. We have left them out of these accounts for the sake of simplicity, and because many of the transitions needed to reach them are not economically credible at present.

Box 1. Catalogues for the state-and transition description of Example 1, diagrammed in Fig 3: Bladder saltbush (Atriplex vesicaria) on heavy clay soil in the Australian Riverine Plain, rainfall $300-400 \mathrm{~mm}$ per year, effective in winter. General accounts in Graetz and Wilson (1984), Noy-Meir (1974).

\section{Catalogue of States}

State I. Dominance $(>20 \%$ cover) of Atriplex vesicaria, lesser contribution of short-perennial Danthonia caespitosa bunchgrass and of various short-lived chenopods.

State II. Dominance of Danthonia and short-lived chenopods, plus significant soil seed bank or seedling population of Atriplex vesicaria. Among the short-lived species dominance varies from year to year but seed banks are presumed continuously present. This state transient, converting to state 1 or state 111 within 2 yr.

State III. As state II but with soil seed bank of Atriplex vesicaria absent. This state appears as satisfactory as state I from the point of view of pastoral production (Leigh and Wilson 1970), and on the heavy clay soils there is no threat of erosion.

\section{Catalogue of Transitions}

Transition 1. Mass death of adult saltbush. Can be brought about in various ways: (a) $100 \%$ defoliation (Leigh and Mulham 1971) by grazing. Perennial saltbush is less palatable than green ephemeral foliage, cured grass and short-lived chenopods (Graetz and Wilson 1980). Therefore there is little grazing pressure until after all these have been consumed. Once this has happened defoliation of the shrubs is rapid, within grazing range of water. In practice it has been found that stocking at $<350$ sheep per watering point avoids this point being reached (Lange et al. 1984). (b) By "dieback", of unknown cause but presumed pathogenic. Frequency uncertain. (c) Possibly by drought, of the order of 1-4 events per century. Observered drought loss for bladder saltbush populations has been in about $200 \mathrm{~mm}$ rainfall (Westoby unpublished observations), and applicability to Riverina sites is uncertain. Even in the more arid regions, drought kill appears to be more important for some subspecies on some land types than for others. (d) Possibly by fire, to which bladder saltbush is completely sensitive. However, this has not been observed in the Riverina and is rare in saltbush shrublands elsewhere. Because the saltbush itself is not very flammable, a large fuel load of ephemerals following exceptional rains is required. This was observed in South Australia following the 1974-5 rains (Lay 1976).

Transition 2. Rainfall to germinate seedlings, followed by unfavorable weather for seedling survival, or by grazing under conditions where the sheep do not have alternative feed. Germination of one cohort requires rain over 2-3 days, at mean temperatures below about 26 deg C. Upwards of $70 \%$ of all years would have one or more germination events of this sort. Seed bank typically will produce 3-4 cohorts of density $>1 \mathrm{~m} \mathrm{~m}^{-2}$, sufficient to establish full-density adult population given good seedling survivorship. Summer drought over 8 months within 3 years of germination, of severity about 10 per century, kills most seedlings. If severity is about $\mathbf{2 0}$ per century or less, seedlings survive (Westoby, unpublished observations).

Transition 3. Rainfall to germinate seedlings, followed by rainfall adequate for seedling survival and growth over 3-5 years (time to reproduction). Absence of grazing heavy enough to knock out saltbush seedlings. See transition 2 for details.

Transition 4. As transition 3, but external source of saltbush seed required.

\section{Opportunities and Hazards}

Since the possible persistent states are of equivalent pastoral value, transitions need be neither encouraged nor resisted.

\section{Allied situntions}

At least $250,000 \mathrm{~km}^{2}$ of southern Australia are potentially dominated by Atriplex vesicaria. All of these have the three states described above, though species composition of the short-lived species and probabilities of rainfall events would vary. Most important variant from the case described above is on duplex soils. Here topsoil is subject to wind erosion if vegetation reaches State III, specifically if perennial shrubs are more than 6 diameters a part (Marshall 1970). Wind crosion reduces the surface to a further state, an unvegetated claypan known as a scald. This is highly undesirable, so transition to State III is to be avoided if possible in this variant. crete states linked by sudden transitions. But even where states are less clearly demarcated from each other or changes are more progressive, states and transitions still provide a practicable way of abstracting and summarizing knowledge about range dynamics without distorting it. The amount of detail lost in a particular description would depend on how many states and transitions were recognized.

We are proposing the state-and-transition formulation because it is a practicable way to organize information for management, not because it follows from theoretical models about dynamics. In consequence, we consider management rather than theoretical criteria should be used in deciding what states to recognize in a given situation. As a general rule, one would distinguish 2 states only if the difference between them represented an important change in the land from the point of view of management. For example, variation due to seasonal phenology of the plants would not normally be subdivided into states, while important changes in the underlying botanical composition would be recognized. It follows that a given rangeland could be described in terms of a greater or lesser number of states and transitions, depending on the nature and objectives of management and on the state of existing knowledge. There would not be a single correct description.

Under the state-and-transition formulation, knowledge about a given rangeland should be organized and expressed in the following forms:

a) A catalogue of possible alternative states of the system.

b) A catalogue of possible transitions from 1 state to another. Each entry would summarize knowledge about the conditions which induce the transition. The conditions could involve particular climatic circumstances, often in conjunction with grazing 


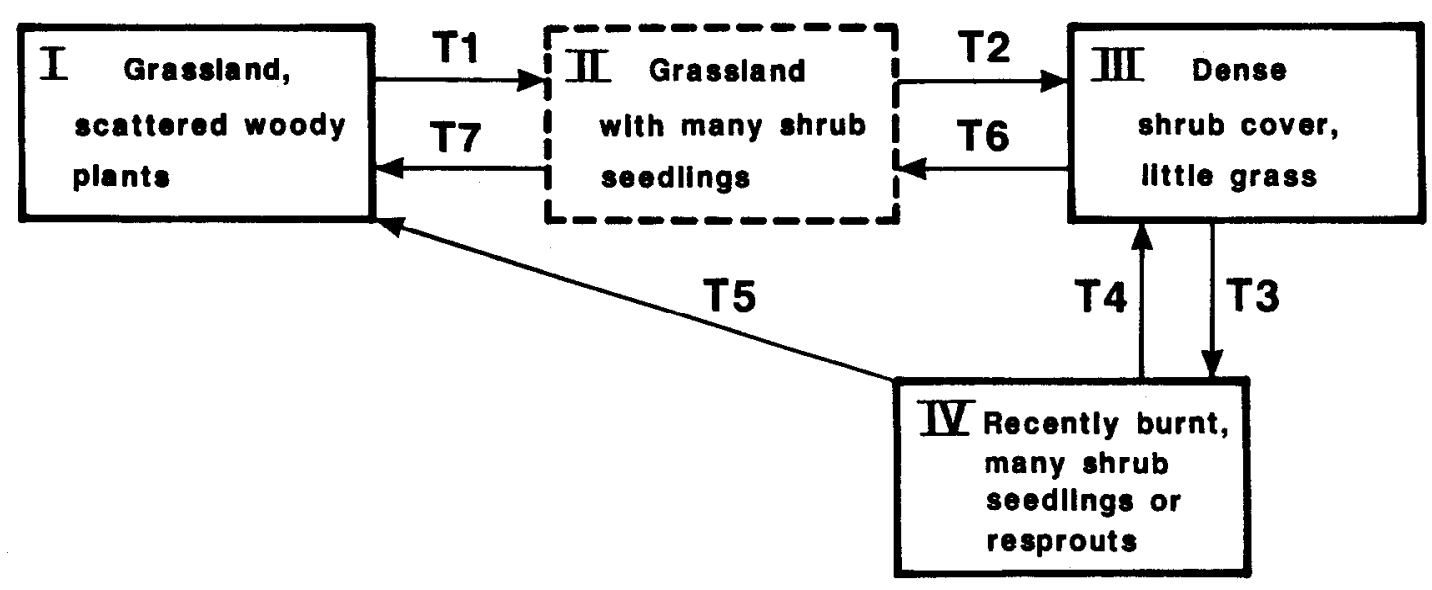

Fig. 4. State-and-transition diagram for Example 2: Semi-arid grassland/woodland in eastern Australia with potential for increase of shrubs. Catalogues in Box 2.

Box 2. Catalogues for the state-and-transition description of Example 2, diagrammed in Fig. 4: Semi-arid grassland/woodland in eastern Australia with potential for increase of shrubs. State of knowledge summarized in Harrington et al. (1984), Hodgkinson and Harrington (1985).

\section{Catalogue of States}

State I. Grassland, scattered woody plants.

State II. Grassland with many shrub seedlings. Transient: converts to State I or State III within a few years.

State III. Dense cover of shrubs with a soil seed bank and/or high potential for vegetative regeneration after fire. Little or no grass.

State IV. Recently burnt, many resprouting shrubs and/or shrub seedlings. Transient: converts to State I or State III within a few years.

\section{Catalogue of Transitions}

Transition 1. Two or more very good rainfall years to produce many shrub seedlings. Frequency 2-5 per century. Substantial fuel of ephemerals and perennial grasses will also be produced. Fuel persistence depends on grazing and on floristics of the understory at the particular location.

Transition 2. Inevitable over time (10-20 years) as shrub seedlings grow and establish a seed bank, in the absence of Transition 7.

Transition 3. Fire, following sufficient rain to provide the fuel of ephemerals. Depending on location and on completeness of shrub dominance, sufficient rain could fall 2-30 times per century. Can be blocked by grazing after the rain to remove the fuel, or by fire suppression.

Transition 4. Inevitable over time as shrub regeneration grows to maturity, in absence of transition 5 . Transition would take about $5 \mathrm{yr}$ if shrubs are vegetative-regenerators, $10-15 \mathrm{yr}$ if a shrub seed bank needed to be reestablished.

Transition 5. Fire, following rains adequate to produce ephemeral fuel, before transition 4 has reestablished the regeneration capacity of the shrub population. Probably less rain required than for transition 3 , due to reduced shrub competition. Blocked by grazing heavy enough to remove the fuel, in which case transition 4 occurs instead.

Transition 6. Fire, following exceptional rains to provide the fuel of ephemerals. This transition found for fire-sensitive shrubs, compare to transition 3 for resprouting shrubs.

Transition 7. Fire or competition from grasses kills shrub seedlings. Blocked by grazing or fire suppression.

\section{Opportunities and Hazards}

State III is highly undesirable relative to State I. Therefore Transition 7 is to be chosen to avoid Transition 2. The short-term costs of this choice are that a large proportion of the herbage produced by good summer rains must be combusted rather than allowing livestock to eat it. In addition there are the costs of executing the burn. From State I, the choice arises 2-5 times per year. If pastures are inspected for shrub seedlings at relevant times, the pastoralist should have 6-12 months notice of the need to burn.

If pastures are in State III, opportunities to burn to make transitions 3 or 6 should be taken. The costs are as for transition 7 , with 2 extra factors to be considered. First, properties in State III are likely to be financially stretched and therefore reluctant to forego short-term income by combusting forage. Second, transitions 3 or 6 need to be followed up by a further burn within a few years. There must exist some risk that fuel will not become available. This risk has not been quantified.

\section{Allied Situations}

Situations with 2 major alternative states, 1 dominated by grasses and 1 by woody plants, are important in semi-arid Africa and southwestern USA as well as in Australia. In America explanations have emphasized fire, and the capacity of grass to provide fuel for it (Brown 1950, Glendening 1952, Humphrey 1958). In Africa there has been interest in an alternative hypothesis which invokes competition for soil water between the 2 layers (Walter 1971, Walker and Noy-Meir 1982, Knoop and Walker 1985). effects and / or fire effects. The level of detail given could vary from extended experimental results about the exact behavior of different subtypes of the rangeland, down to a note describing the undocumented opinions of an experienced rancher.

c) A catalogue of opportunities-climatic circumstances under which management action such as fire, heavy grazing, removal of grazing, etc., can produce a favorable transition - and of hazardsclimatic circumstances under which failure to burn, heavy grazing, etc., could produce an unfavorable transition. Sometimes people with different social criteria or management objectives might not agree which states were more desirable than which. Therefore a single catalogue of factually-described states might be associated with more than 1 catalogue of opportunities and hazards.

\section{Examples Expressed in Terms of States and Transitions}

A simple example is perennial saltbush shrubland or grassland in the temperate Australian Riverina (Fig. 3 and Box 1). This vegetation occurs on heavy clay soils with rainfall of $300-400 \mathrm{~mm}$ per year. It has 2 persistent states and 1 transient state. Transition from the persistent shrub-dominated to the persistent grassdominated state can be driven by grazing. However, the situation is not well described by the range succession model. Elimination of 
adult bladder saltbush under grazing does not occur progressively. Rather it comes about quickly when specified conditions occur. Transition from the grass-dominated state back to a stand of bladder saltbush does not occur by removal of grazing.

The critical situation in this system arises after the rangeland reaches the transient State II. The system will change either to State I or to State III within a few years. It is thought that destocking will reduce the probability of going to State III rather than State I (Graetz and Wilson 1984), but this has not been experimentally tested. In this particular variant of bladder saltbush country, State III is not inferior for pastoral production. Livestock managers would not necessarily be concerned which transition was made. The saltbush dominated State I has conservation value, however.

A more complex example is semi-arid woodland with grass or shrub understory (Fig. 4 and Box 2). Alternative persistent states arise because grass understory is favored by fire and provides fuel, while shrub understory suppresses fuel and is sensitive to repeated fires. The critical management decisions arise after sufficient rain has fallen to produce a fuel of ephemerals. Failure to burn at such times risks large-scale establishment of woody plants, or misses the opportunity to control woody plants already present. Grazing consumes fuel, and so narrows the windows of opportunity for burning.

These 2 examples illustrate how in some rangelands the range succession model can lead range research in unhelpful directions. It is true that in both cases grazing was important in vegetation changes which followed the introduction of European livestock. However, the effect of grazing could not be construed as a steady pressure. Attempts to establish an equilibrium under set stocking applied stocking rates which probably were unnecessarily conservative much of the time, but still too high at critical times. Most importantly, destocking failed to reverse the changes to which grazing had contributed. These 2 rangeland types are now quite well understood at a scientific level. However, the administrative structures which seek to guide pastoralists towards good land management still operate in terms of recommended grazing capacity and measuring condition and trend.

A third example is South African tall grassveld (Fig. 5 and Box 3). We include this example to show how a state-and-transition formulation can be used even when there are uncertainties and disagreements as to what states should be recognized and what processes lead to transitions between them. The sequence of states II-HII-VI could be described satisfactorily in terms of a single continuum, as in the range succession model. Themeda is a classic decreaser species and Aristida congesta and Microchloa caffra are classic increasers. The key problem on these rangelands is that if grazing is sufficiently selective against palatable species, there can be a shift to dominance by unpalatable species. This State IV does not have less ground cover than State II, nor are the plants less perennial. Most important from a practical point of view, reduced grazing pressure does not lead to the palatable species recovering dominance with any promptness. These complications have been recognized by distinguishing separate groups of increaser species (Tainton 1981).

An alternative hypothesis emphasizes that grazing has different effects depending on plant phenology (Walker et al. 1986). In particular, early plant growth is dominated by unpalatable species in some years and by palatable species in other years, depending when the first effective rains fall in relation to the internallyprogrammed seasonality of the species. Palatable species can be favored by destocking during years when the timing of rainfall coincides with the maximum growth phase of these species. Destocking during a year when rainfall timing favors unpalatable species will not achieve the aim of increasing the proportion of palatable species.

In summary, the range succession model is unsatisfactory in this instance not so much because of the importance of sudden transitions and extreme events, but more because it is difficult to arrange the possible states of the vegetation in a single linear continuum. The state-and-transition formulation is capable of accommodating this problem. It also identifies accurately the key issues for research-whether transition 5 can be achieved at all, if so by what means, and whether transition 8 followed by transition 3 is more practicable. The catalogue formulation (Box 3) is different from the range succession model in that it does not compel the author to make a definite assessment as to what transitions are possible. $\mathbf{A}$ catalogue entry can accomodate alternative hypotheses about transitions, including the possibility that a particular transition does not happen.

\section{Discussion}

Weaknesses of the range succession model are most apparent in arid and semiarid rangelands, where episodic events are important and influences of grazing and intrinsic vegetation change act intermittently. The state-and-transition model is adapted to cope with such characteristics.

Suppose a state-and-transition approach were adopted for a particular rangeland: would research, management and administration be different, compared to practices under the range succession model? We believe they would be different in some significant ways.

Research would aim to construct the catalogue of possible states of any given rangeland. It should be borne in mind that some possible states might not have existed during the period range scientists have studied the range type. Research would also need to assess the productivity - pastoral, recreational, water-yield, etc.of each possible state. These research objectives are not very different from those indicated by the range succession model.

The state-and-transition model would put high priority on experimental tests of hypotheses about the various transitions. Many of these transitions can only occur given an appropriate climatic sequence, plus the hypothesized management with respect to grazing, fire, seeding, etc. Experiments on such transitions would be planned on a contingency basis. They would be put into operation not on a fixed research schedule but when the relevant climatic conditions arose. Research agencies would keep lists of such experiments, planned ready to carry out when the opportunity presented itself. They would also need to keep a percentage of their people and money resources available, not irretrievably committed to other activities. By the time a proposal had been written and money allocated from the next funding cycle, the opportunity would have passed. This is why few such opportunistic experiments have been done.

Under the state-and-transition model managers would see themselves as facing an oncoming stream of events, a mixture of opportunities and hazards. Their objective would be to seize the opportunities and evade the hazards, so far as possible. To do this effectively it would be important to have a good statistical picture of the stream of events. The state-and-transition model would therefore put research emphasis on estimating the probabilitiesfrequency per year, per decade or per century-of the climatic circumstances relevant to particular transitions. It is worth noting that the climate is expected to change substantially over the next 50 yr due to greenhouse warming. Range science will need to cope with those changes. Under the state-and-transition model, effects of climate change would be expressed as changed probabilities of particular climatic circumstances.

Management based on the range succession model has sought to determine a recommended carrying capacity which will be applied 


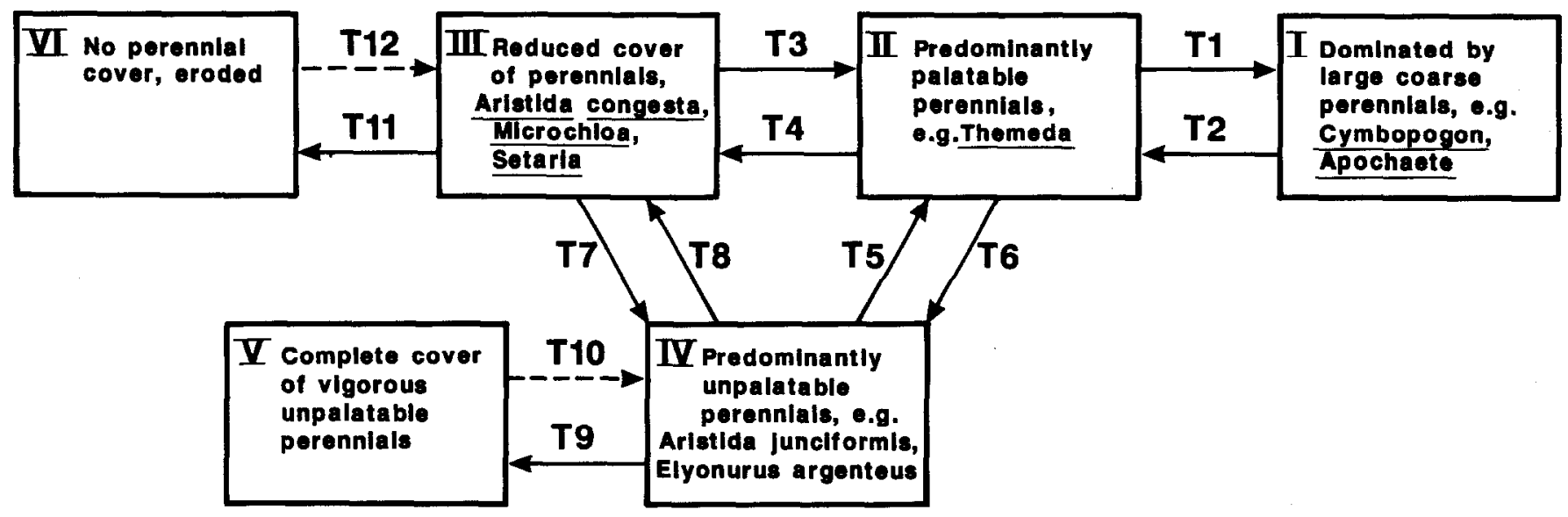

Box 3. Catalogues for the state-and transition description of Example 3, diagrammed in Fig. 5: Tall grassveld (both moist and dry) in South Africa. Description from Tainton (1981) and personal knowledge of Walker.

\section{Catalogue of States}

State I. Dominated by large, coarse perennial grasses, e.g. Cymbopogon excavatus, Apochaete hispida (so-called "increaser 1" species).

State II. Dominated by palatable perennial grasses such as Themeda triandra, Eragrostis racemosa, E. capensis (so-called "decreaser" species). Lesser percentages of various increaser species types.

State III. Dominated by grasses such as Aristida congesta, Microchloa caffra, Setaria flabellata (so-called "increaser 2" species), with substantial bare ground, and many annuals and microperennials (shortgrasses).

State IV. Dominated by large, established tufts of unpalatable grasses such as Aristida junciformis, Elyonurus argenteus (so-called "increaser 3" species) with little bare ground. Lesser but significant amounts of decreaser and increaser 2 species (see States II and III).

State $V$. Vigorous full cover of increaser 3 species (see State IV).

State VI. Bare ground and annuals.

\section{Catalogue of Transitions}

Transition 1. According to one hypothesis is due to "overresting"; others regard State I as a variant of State II perhaps due to local soil effects; others again would group State I with State IV.

Transition 2. Light grazing.

Transition 3. Complete or nearly-complete relaxation of grazing pressure.

Transition 4. Moderate-to-heavy grazing imposed in a way which does not allow animals to avoid eating unpalatable species.

Transition 5. According to one hypothesis does not occur, since palatable grasses are not capable of increasing in the face of established dominance by the unpalatable perennials. Others believe this transition does occur given total destocking, but is very slow. There is also a hypothesis that relative competitive advantage can be shifted by exact timing of grazing at the beginning of a wet season. Under this hypothesis, which grass grows best varies from year to year, depending on when the first rain falls and on the sequence of early rains. Thus transition 5 could be assisted by selecting years in which the palatable grasses are favoured and grow best, and grazing very lightly during this period of early growth.

Transition 6. Moderate grazing which allows animals to choose palatable species and avoid unpalatable species; by this means competitive advantage shifts to the unpalatable "increaser 3" species. Most commonly this would come about under moderate set-stocking. Another factor might be early-season grazing in years when palatable grasses are disadvantaged by the pattern of rainfall (see Transition 5).
Transition 7. Comes about if grazing pressure is relaxed but not as completely as for Transition 3, so that while biomass and ground cover accumulate in all plant groups, there is selection against palatable species.

Transition 8. Very heavy grazing in short bursts, and/or burning. It is not well understood what exact amounts or sequences of heavy grazing or fire can counter the competitive advantage of unpalatable species without demolishing the capacity of the palatable perennials to regenerate.

Transition 9. Same processes as Transition 6, continuing to the point where dominance by unpalatable grasses is complete.

Transition 10. Very slow, or in practical management terms not a feasible transition, because in State V virtually all the sward is occupied by large, vigorous, established tussocks of unpalatable grasses.

Transition 11. Continued heavy grazing to the point where neither tussocks nor seed bank of perennial grasses remain, and soil erosion is serious.

Transition 12. Only possible with soil reclamation work and reseeding.

\section{Opportunities and Hazards}

There are 2 principal routes by which the productive capacity of the rangeland can be degraded. One is simple overgrazing, down the route from State II to State III and ultimately to State VI. The more serious hazard is the route from State II to State IV and ultimately to State V. This is a more serious hazard both because transition 6 can be made at quite moderate levels of stocking compared to transition 4 , and because recovery from State IV is much slower than from State III. An important variant hazard is that if one seeks to recover from State III to State II by reducing grazing pressure, and if that is done in such a way that the remaining grazing is selective against palatable species, there is a serious risk of making transition 7 rather than the desired transition 3.

Two types of opportunity for returning from State IV to State II deserve mentioning. One is the possibility that the return can be made much more quickly via transition 8 followed by transition 3 than by transition 5 . The other is the possibility that there exist windows of time in some years at the beginning of growing seasons in which unpalatable grasses are more vulnerable to grazing than palatable grasses, and vice versa in other years. By identifying such years and grazing heavily during such windows of time it might be possible to direct grazing pressure strongly against unpalatable species.

\section{Allied Situations}

Rangelands with similar features occur in British hill pastures, which become dominated by the unpalatable Nardus if grazed in a way which selects too strongly against palatable Agrostis and Festuca species. 
on a continuing basis. It has aimed to restrict this stocking rate so as to avoid rangeland deterioration. The main management tool has thus been used with a defensive orientation. In contrast the state-and-transition formulation leads to policies which are opportunistic (Westoby 1980, Walker et al. 1986) and oriented towards seeking positive improvement in the state of the vegetation.

What of government administrators who oversee and regulate the activities of individual managers? The state-and-transition model should influence them to:

1. Drop the assumption that inaction or conservative grazing is safe. In many situations moderate grazing leads to range deterioration. Sometimes very heavy grazing is a constructive thing to do. Often, burning is a constructive thing to do. Legislation and regulations need to free managers to intervene positively. Where possible, regulation should focus not on stocking rates but on changes in the actual state of the land or the vegetation.

2. Reorganize assistance schemes-drought loans, financial support for temporarily moving livestock off a property, etc. - so that managers can get help less often but in larger amounts. To seize opportunities for constructive transitions and avoid hazards, managers will need to take strong actions, but only occasionally. They may need to destock totally on occasions which arise once a decade, rather than destocking by $10 \%$ on a continuing basis.

Unfortunately, hazards or opportunities often will arise at the same time for many of the managers in a region. Probably it will be administratively and politically difficult to provide large amounts of help for many managers at the same time.

3. Orient extension activities to letting managers in a region know when an opportunity of a transition is offering or a hazard is threatening, and to informing them what they can do about it.

These are the general directions of administrative reform indicated by the state-and-transition model. We appreciate that many practical difficulties lie in the way of modifying the administrative and regulatory approach to rangelands in these directions. Nevertheless the problems and possibilities deserve to be discussed further among rangeland professionals.

\section{Literature Cited}

Acocks, J.P.H. 1953. Veld types of South Africa. 2nd edn. Mem. Bot. Surv. S. Afr. 40, Pretoria.

Anderson, J.E. 1986. Development and structure of sagebrush steppe plant communities. p. 10-12. In: P.J. Joss, P.W. Lynch and O.B. Williams (eds), Rangelands: A Resource Under Siege. Australian Acad. Sci., Canberra, Australia.

Biswell, H.H. 1956. Ecology of California grasslands. J. Range Manage. 9:19-24.

Brown, A.L. 1950. Shrub invasion of southern Arizona desert grassland. J. Range Manage. 3:172-177.

Buffington, L.C., and C.H. Herbel. 1965. Vegetation changes on a semidesert grassland range from 1858 to 1963 . Ecol. Monog. 35:139-164.

Clements, F.E. 1916. Plant succession: an analysis of the development of vegetation. Carnegie Inst. Washington Pub. 242:1-512.

Connell, J.H., and R.O. Slatyer. 1977. Mechanisms of succession in natural communities and their role in community stability and organization. Amer. Natur. 111:1119-1144.

Crawley, M.J. 1983. The dynamics of animal-plant interactions. Blackwell, Oxford.

Crisp, M.D. 1978. Demography and survival under grazing of three Australian semi-desert shrubs. Oikos 30:520-528.

Crisp, M.D., and R.T. Lange. 1976. Age structure, distribution and survival under grazing of the arid-zone shrub Acacia burkittii. Oikos 27:86-92.

Drury, W.H., and I.C.T. Nisbet. 1973. Succession. J. Arnold Arboretum, Harvard Univ. 54:331-368.

Dyksterhuis, E.J. 1949. Condition and management of rangeland based on quantitative ecology. J. Range Manage. 2:104-115.

Dyksterhuls, E.J. 1958. Ecological principles in range evaluation. Bot. Rev. 24:253-272.

Ellison, L. 1960. Influence of grazing on plant succession of rangelands. Bot. Rev. 26:1-78.
Foin, T.C. 1986. Succession, climax and range evaluation in the California coastal prairie ecosystem. p. 5-7. In. P.J. Joss, P.W. Lynch and O.B. Williams (eds), Rangelands: A Resource Under Siege. Australian Sci., Canberra, Australia.

Gardner, J.L. 1950. Effects of thirty years of protection from grazing in desert grassland. Ecology 31:44-50.

Glendening, G.E. 1952. Some quantitative data on the increase of mesquite and cactus on a desert range in southern Arizona. Ecology 33:319-328.

Graetz, R.D., and A.D. Wilson. 1980. Comparison of the diets of sheep and cattle grazing a semi-arid chenopod shrubland. Aust. Rangeland J. 2:67-75.

Graetz, R.D., and A.D. Wilson. 1984. Saltbush and bluebush, p. 209-222. In: G.N. Harrington, A.D. Wilson, and M.D. Young (eds.) Management of Australia's Rangelands. CSIRO, Melbourne.

Grifrin, G.F., and M.H. Friedel. 1985. Discontinuous change in central Australia: some implications of major ecological events for land management. J. Arid Environments 9:63-80.

Hanson, H.C. 1957. The use of basic principles in the classification of range vegetation. J. Range Manage. 10:26-33.

Harrington, G.N., A.D. Wilson, and M.D. Young (eds). 1984. Management of Australia's Rangelands. CSIRO, Melbourne.

Heady, H.F. 1958. Vegetational changes in the California annual type. Ecology 39:402-415.

Heady, H.F. 1975. Rangeland Management. McGraw-Hill, New York.

Hodgkinson, K.C., and G.N. Harrington. 1985. The case for prescribed burning to control shrubs in eastern semi-arid woodlands. Aust. Rangeland J. 7:64-74.

Humphrey, R.R. 1945. Some fundamentals of the classification of range condition. J. Forest. 43:646-647.

Humphrey, R.R. 1958. The desert grassland, a history of vegetation change and an analysis of causes. Bot. Rev. 24:193-252.

Jameson, D.A. 1988. Modelling rangeland ecosystems for monitoring and adaptive management, p. 189-221. In: P. Tueller (ed), Vegetation Science Applications for Rangeland Analysis and Management. Kluwer Academic Publishers, Dordrecht.

Knoop, W.T., and B.H. Walker. 1985. Interactions of woody and herbaceous vegetation in a southern African savanna. J. Ecol. 73:235-253.

Lange, R.T., and C.R. Graham. 1983. Rabbits and the failure of regeneration in Australian arid zone Acacia. Aust. J. Ecol. 8:377-381.

Lange, R.T., A.D. Nicolson, and D.A. Nicolson. 1984. Vegetation management of chenopod rangelands in South Australia. Aust. Rangeland J. 6:46-54.

Lay, B.G. 1976. Fire in the pastoral country. J. Agr. S. Aust. 79:9-14.

Le Houerou, H.N. 1972. Africa-the Mediterranean region, p. 26-36. In: C.M. McKell et al. (eds.), Wildland Shrubs-Their Biology and Utilization. U.S. Forest Serv. Gen. Tech. Rep. INT-1.

Leigh, J.H., and W.E. Mulham. 1971. The effect of defoliation on the persistence of Atriplex vesicaria. Aust. J. Agr. Res. 22:239-244.

Leigh, J.H., and A.D. Wilson. 1970. Utilization of Atriplex species by sheep. p. 97-104. In: R. Jones (ed), The Biology of Atriplex. CSIRO, Canberra.

Lewis, J.K. 1969. Range management viewed in the ecosystem framework, p. 97-187. In: G.M. Van Dyne (ed), The Ecosystem Concept in Natural Resource Management, Acad. Press, N.Y.

Mentis, M.T. 1986. Range dynamics by classical succession and strategic modelling, p. 19-21. In. P.J. Joss, P.W. Lynch, and O.B. Williams (eds), Rangelands: A Resource Under Siege. Australian Acad. Sci., Canberra, Australia.

Marshall, J.K. 1970. Assessing the protective role of shrub-dominated rangeland vegetation against soil erosion by wind, p. 19-23. In: Proc. 1lth Int. Grassl. Congr., Surfer's Paradise, Australia.

May, R.M. 1977. Thresholds and breakpoints in ecosystems with a multiplicity of stable states. Nature 269:471-477.

Naveh, Z. 1967. Mediterranean ecosystems and vegetation types in California and Israel. Ecology 48:445-459.

Neilson, R.P. 1986. High-resolution climatic analysis and Southwest biogeography. Science 232:27-34.

Nobel, I.R. 1986. The dynamics of range ecosystems, p. 3-5. In: P.J. Joss, P.W. Lynch and O.B. Williams (eds), Rangelands: A Resource Under Siege. Australian Acad. Sci., Canberra, Australia.

Noble, I.R., and R.O. Slatyer. 1980. The use of vital attributes to predict successional changes in plant communities subject to recurrent disturbance. Vegetatio 43:5-21.

Norris, J.J. 1950. Effect of rodents, rabbits and cattle on two vegetation types in semidesert range land. Agr. Exp. Sta. Bull. 353, New Mexico State Univ. 
Noy-Meir, 1. 1974. Multivariate analysis of the semiarid vegetation in Southwestern Australia II. Vegetation catenae and environmental gradients. Aust. J. Bot. 22:115-140.

Noy-Meir, I. 1975. Stability of grazing systems: an application of predatorprey graphs. J. Ecol. 63:459-481.

Noy-Meir, 1. 1978. Stability in simple grazing models: effects of explicit functions. J. Theor. Biol. 71:347-380.

Noy-Meir. I. 1981. Theoretical dynamics of competitors under predation. Oecologia 50:277-284.

Noy-Meir, I. 1982. Stability of plant-herbivore models and possible application to savanna. p. 591-609. In: B.J. Huntley and B.H. Walker (eds), Ecology of Tropical Savannas. Springer-Verlag, Berlin.

Paulsen, H.A., Jr., and F.N, Ares. 1962. Grazing values and management of black grama and tobosa grasslands and associated shrub ranges of the Southwest. USDA Forest Serv. Tech. Bull. 1270.

Parker, K.W. 1954. Application of ecology in the determination of range condition and trend. J. Range Manage. 7:14-23.

Price, P.W. 1980. Evolutionary biology of parasites. Princeton University Press, Princeton, N.J.

Price, P.W., C.N. Slobodchikoff, and W.S. Gaud (eds.) 1984. A new ecology: Novel approaches to interactive systems. Wiley, New York.

Rice, B., and M. Westoby. 1978. Vegetative responses of some Great Basin shrub communities protected against jackrabbits or domestic stock. J. Range Manage. 31:28-34.

Rawes, M. 1981. Further results of excluding sheep from high-level grasslands in the north Pennines. J. Ecol. 69:651-669.

Robertson, J.H. 1971. Changes on a grass-shrub range in Nevada ungrazed for 30 years. J. Range Manage. 24:397-400.

Sampson, A.W. 1917. Succession as a factor in range management. J. Forest. 15:593-596.

Sampson, A.W. 1919. Plant succession in relation to range management. USDA Bull. 791.

Smeins, F.E., T.W. Taylor, and L.B. Merrill. 1976. Vegetation of a 25-year exclosure on the Edwards Plateau. Texas J. Range Manage. 29:24-29.

Smith, D.A., and E.M. Schmutz. 1975. Vegetative changes on protected versus grazed desert grassland ranges in Arizona. J. Range Manage. 28:453-458.

Smith, E.L. 1988. Successional concepts in relation to range condition assessment, p. 113-133. In: Paul Tueller (ed), Vegetation Science Applications for Rangeland Analysis and Management. Dr. W. Junk, The Hague.

Stoddart, L.A., and A.D. Smith. 1943. Range management. McGraw-Hill, New York.

Stoddart, L.A., and A.D. Smith. 1955. Range management. 2nd Edition. McGraw-Hill, New York.

Stoddart, L.A., A.D. Smith, and T.W. Box. 1975. Range management. 3rd Edition. McGraw-Hill, New York.
Strong, D.R., D. Simberloff, L.G. Abele, and A.B. Thistle (eds). 1984. Ecological communities: Conceptual issues and the evidence, Princeton Univ. Press, Princeton, N.J.

Tainton, N.M. 1981. Veld and pasture management in South Africa. Shuter and Shooter, Pietermaritzburg, South Africa.

Tueller, P.T. 1973. Secondary succession disclimax, and range condition standards in desert shrub vegetation, p. 57-65. In: D.N. Hyder (ed), Arid Shrublands, Soc. Range Manage., Denver.

Turner, G.T. 1971. Soil and grazing influences on a salt-desert shrub range in western Colorado. J. Range Manage. 24:397-400.

Walker, B.H. (In Press). Diversity and stability in ecosystem conservation, p. $\quad$ - In: D. Western and M. Pearl (eds) Conservation Biology for the Next Century. Oxford Univ. Press, New York.

Walker, B.H. Autecology, synecology, climate and livestock as agents of rangeland dynamics. Australian Rangeland J. 10:69-75.

Walker, B.H., D. Ludwig, C.S. Holling, and R.M. Peterman. 1981. Stability of semi-arid savanna grazing systems. J. Ecol. 69:473-498.

Walker, B.H., and I. Noy-Meir. 1982. Aspects of the stability and resilience of savanna ecosystems, p. 577-590. In: B.J. Huntley and B.H. Walker (eds), Ecology of Tropical Savannas. Springer. Berlin.

Walker, B.H., D.A. Matthews, and P.J. Dye. 1986. Management of grazing systems-existing versus an event-orientated approach. South Afr. J. Sci. 82:172.

Walter, H. 1971. Ecology of tropical and subtropical vegetation. Oliver and Boyd, Edinburgh.

Weaver, J.E., and F.E. Clements. 1938. Plant ecology. McGraw-Hill, New York.

West, N.E. 1988. Plant synecology in the service of rangeland management. p. 11-27. In: P. Tueller (ed), Vegetation Science Applications for Rangeland Analysis and Management. Kluwer Academic Publishers, Dordrecht.

West, N.E., F.D. Provenza, P.S. Johnson, and M.K. Owens. 1984. Vegetation change after 13 years of livestock grazing exclusion on sagebrush semidesert in west central Utah. J. Range Manage. 37:262-264.

Westoby, M. 1974. An analysis of diet selection by large generalist herbivores. Amer. Natur, 108:290-304.

Westoby, M. 1980. Elements of a theory of vegetation dynamics in arid rangelands. Israel J, Bot. 28:169-194.

Wiens, J.A. 1977. On competition and variable environments. Amer. Sci. 65:590-597.

Williams, O.B. 1970. Population dynamics of two perennial grasses in Australian semi-arid grassland. J. Ecol. 58:869-875.

Williams, O.B., and R. Roe. 1975. Management of arid grasslands for sheep: plant demography of six grasses in relation to climate and grazing. Proc. Ecol. Soc. Aust. 9:142-156.

Wilson, A.D., G.N. Harrington, and I.F. Beale. 1984. Grazing management, p. 129-139. In: G.N. Harrington, A.D. Wilson and M.D. Young (eds), Management of Australia's Rangelands. CSIRO, Melbourne. 